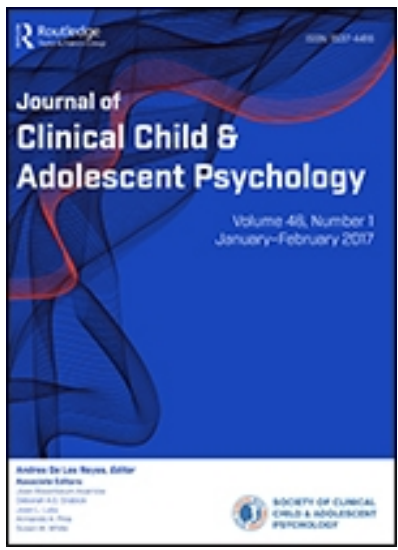

\title{
Parent and Friend Relationship Quality and Trajectories of Loneliness during the First Year of College
}

\begin{tabular}{|r|l|}
\hline Journal: & Journal of Clinical Child and Adolescent Psychology \\
\hline Manuscript ID & Draft \\
\hline Manuscript Type: & Empirical Article \\
\hline Keywords: & $\begin{array}{l}\text { Adolescence, Emerging Adulthood, Loneliness, Parent Relationships, } \\
\text { Friend Relationships }\end{array}$ \\
\hline \multicolumn{2}{|l}{} \\
\hline
\end{tabular}

\section{SCHOLARONE ${ }^{m}$ \\ Manuscripts}


Parent and Friend Relationship Quality and Trajectories of Loneliness during the First Year of College 


\begin{abstract}
The transition from adolescence into adulthood is an understudied yet important phase of development. For many individuals, this transitional stage involves profound sociocultural adjustments, including the transition to college. The beginning of college often involves both challenges and opportunities as one adjusts to new academic and social environments. Individuals may be particularly vulnerable to loneliness during this transition, putting them at risk for both psychological and academic difficulties. Parent and friend relationships are potential protective factors against loneliness given their positive association with psychosocial adjustment. The present longitudinal study assessed the comparative effects of self-reported parent and friend relationship quality on loneliness, both at baseline and over time using 292 longitudinal data points, in a cohort of first-year college students ( $N=101$ individuals). At baseline, parent and friend relationship quality were negatively associated with loneliness. The magnitude of the association between friend relationship quality and loneliness was stronger than parent relationship quality and loneliness. Longitudinal data revealed that friend, but not parent, relationship quality interacted with the passage of time, such that the effects of friend relationship quality on loneliness attenuated over the course of two months. By contrast, parent relationship quality continued to predict lower loneliness two months post-baseline. These results highlight the importance of close relationships and suggest that targeting relationship quality particularly with parents- could be effective in helping youth transition out of the home successfully. Findings are discussed in terms of potential avenues for prevention and intervention aimed at optimizing successful adjustments to college.
\end{abstract}

Key words: Adolescence; Emerging Adulthood; Loneliness; Parent Relationships; Friend Relationships 


\section{Introduction}

Human development features an abundance of transitions_-periods in which biological, social, or cultural contexts change quickly over a short amount of time. One transition that is particularly important for adjustment over the lifespan is the transition from adolescence to adulthood (Arnett, 2000; 2014). While decades-old questions and debates about when adolescence ends persist today (Cohen, Bonnie, Taylor-Thompson, \& Casey, 2015; Cohen, Breiner, Steinberg, Bonnie, Scott, Taylor-Thompson, Rudolph, Chein, Richeson, Heller, Silverman, Dellarco, Fair, Galván, \& Casey, 2016; Gould, 1972; Levinson, 1986), scientists generally agree that the transitional period between adolescence and adulthood is a critical yet understudied window that has important consequences for adjustment (Inguglia, Ingoglia, Liga, Coco, \& Cricchio, 2015; Lapsley \& Hill, 2010; Nelson, 2013; Tucker, Ellickson, Orlando, Martino, \& Klein, 2005; Wood et al., 2018). The importance of this window is underscored not only by the panoply of changes in interpersonal relationships, sociocultural environments, and educational/occupational expectations - but also by its endproduct: adult independence. This phase is further complicated by the onset of many forms of psychopathology during this interval (Merikangas et al., 2010.), trends that emerge during a period of decreased utilization of mental health services (Merikangas et al., 2011).

For many youth, a key event in the transition to adulthood is beginning college, which often involves multiple changes, including moving away from home and navigating a novel social context (Shaver, Furman \& Buhrmester, 1985). While rich in opportunity, these changes increase vulnerability to loneliness which in turn affects physical, academic, and psychological well-being (Hawkley \& Cacioppo, 2010; Lin \& Huang, 2012; Richardson, Elliott, \& Roberts, 2017). Therefore, it is vital to identify protective factors against loneliness during the first year of college. Strong relationships with parents and friends are likely protective factors against loneliness given their association with psychosocial adjustment in young adults (Buote, Pancer, Pratt, Adams, Birnie-Lefcovitch, Polivy, \& Winter, 2007; Holt, Mattanah, \& Long, 2018; Zawadzki, Graham, \& Gerin, 2013). However, little research has assessed the comparative effects of parent and friend relationship quality on subjective loneliness during the first year of college. Additionally, few studies have characterized normative trajectories of loneliness across freshman year of college. The present study sought to fill these gaps in the literature by examining the association between parent and friend relationship quality and loneliness during 
the first year of college while simultaneously quantifying normative trajectories of loneliness during this period. Such work is crucial for crafting interventions aimed at supporting successful adjustment in college, and, more broadly, the transition to full independence.

Although a time for self-discovery and new experiences, entering college is also a source of stress for many (Gall, Evans, \& Bellerose, 2000; Hurst, Baranik, \& Daniel, 2013). It is common for new college students to struggle with the discrepancy between their expectations of college and their actual experiences (Gerdes \& Mallinckrodt, 1994; Smith \& Wertlieb, 2005). Individuals may also struggle with an uneasy sense of being caught in developmental limbo between adolescence and adulthood, by still being reliant on their parents for some aspects of life while being independent in other domains (Arnett, 2000). For many, their first year of college is the first time living away from their parents and simultaneously involves making new friends in college while maintaining relationships with friends back home. For these reasons and more, the first year of college, particularly the initial transition, is frequently characterized by normative decreases in psychosocial well-being and increases in psychological distress (Conley, Kirsch, Dickson \& Bryant, 2014). What is comparatively less studied is how this distress persists across the first year of college and what factors might exacerbate or help attenuate this distress.

Collectively, the changes that occur during the first year of college can increase one's vulnerability to loneliness (Diehl, Jansen, Ishchanova, \& Hilger-Kolb, 2018; Larose \& Boivin, 1998; Shaver et al., 1985). Loneliness is defined here as the distressing feeling that results from the perception that one's social needs are not being met or a discrepancy between perceived quality and desired quality of relationships (Perlman \& Peplau, 1998; Russell, Cutrona, Rose, \& Yurko, 1984). Loneliness is not confined to any particular developmental period but it is particularly prominent in young adulthood, perhaps especially for first-year college students (Qualter, Vanhalst, Harris, Van Roekel, Lodder, Bangee, Maes, \& Verhagen, 2015; Mund, Freuding, Möbius, Horn, \& Neyer, 2019). Loneliness peaks during the first year of college relative to later years of college (Diehl et al., 2018; Ponzetti Jr, 1990; Wei, Russell, \& Zakalik, 2005; Özdemir \& Tuncay, 2008), particularly for individuals who move away for college (Larose \& Boivin, 1998). While some degree of loneliness is normative during the first year of college (Cutrona, 1982), elevated levels of loneliness have been linked to cardiovascular health risk, elevated cortisol levels, diminished academic achievement, worse sleep quality, daytime dysfunction, and elevated depressive symptomatology in young adults (Cacioppo, Hawkley, 
Crawford, Ernst, Burleson, Kowalewski, Malarkey, Van Cauter, \& Berntson, 2002; Caspi, Harrington, Moffitt, Milne, \& Poulton, 2006; Matthews, Danese, Gregory, Caspi, Moffitt, \& Arseneault, 2017; Pressman, Cohen, Miller, Barkin, Rabin, \& Treanor, 2005; Rotenberg \& Morrison, 1993; Zawadzki et al., 2013). Further evidence also suggests that loneliness predicts college drop-out, over and above college GPA, and appears to indirectly influence use of campus counseling resources via elevated levels of depression and anxiety (Center for Collegiate Mental Health, 2019; Richardson et al., 2017; Rotenberg \& Morrison, 1993).

Given its various negative outcomes, it is imperative to identify buffers against loneliness during the first year of college. Relationships with parents and friends are potential buffers against loneliness given their association with psychosocial adjustment. Having high-quality relationships with parents and friends helps fulfill the socioemotional needs of young adults (Larose \& Boivin, 1998; Swenson, Nordstrom, \& Hiester, 2008), which in turn lessens their vulnerability for loneliness (Larose, Guay, \& Boivin, 2002; Lee \& Goldstein, 2016). Parental relationships improve and stabilize during young adulthood and there is a stronger connection to family during this time compared to earlier adolescence (Holt et al., 2018; Tubman \& Lerner, 1994). Relationships with parents improve normatively over the first year of college (Shaver et al., 1985), and high parent-child relationship quality during this period has been linked to better academic, psychological and social well-being in college (Cutrona, Cole, Colangelo, Assouline, \& Russell, 1994; Holahan, Valentiner, \& Moos, 1994; Holt et al., 2018).

Friends can provide a complementary source of social support to parents during the first year of college (Lee \& Goldstein, 2016), in part because young adults are more inclined to confide in and seek day-to-day emotional support from their friends than parents (Szwedo, Hessel, Loeb, Hafen, \& Allen, 2017; Wilcox, Winn, \& Fyvie-Gauld, 2005; Wilks, 1986). Friends may be particularly important in college for helping individuals achieve their social and academic goals while simultaneously establishing a deeper sense of belongingness to their university (Buote et al., 2007; Holt et al., 2018). Given that individuals' friendship networks may change dramatically during the first few months of college, it stands to reason that friendships established prior to college are initially helpful at buffering against loneliness whereas those established after the onset of college may have greater impacts on loneliness over time (Swenson et al., 2008). Friendships established prior to college decrease in size and quality during the first year of college (Shaver et al., 1985; Oswald \& Clark, 2003) which can leave young adults 
without support if they do not develop new friendships or have strong family support networks. Importantly, friend relationship quality, as opposed to the number of friends, is a better predictor of loneliness and thus the focus of the present study was on friendship quality rather than social network size (Cutrona, 1982).

Current Study. While evidence suggests that both parent and friendship relationship quality can buffer against loneliness during the first year of college, little research has compared the relative impacts of parent and friend relationship quality, in the same sample, on well-being during freshman year as well as whether their effects are additive or interactive. As such, the present study sought to examine how loneliness during the first year of college varies depending on parent and friend relationship quality. Specifically, we were interested in determining the associations between parent and friend relationship quality and loneliness in addition to whether one type of relationship was more strongly associated with loneliness outcomes. This feature of our study is noteworthy because most prior studies focus on relationship quality with close others as a whole, or with only one particular type of social other (solely friends, or solely parents) (Zawadzki et al., 2013). Studying the unique contributions of both parents and friends has the added benefit of helping identify eventual mechanistic specificity. Furthermore, given that most prior work on loneliness during the first year of college has focused on the effect of loneliness on other adjustment outcomes or has assessed loneliness at only one or two timepoints (e.g., Zawadzki et al., 2013), we sought to quantify normative longitudinal trajectories of loneliness for the first time. These study aims resulted in four a priori hypotheses, as well as an exploratory, post hoc (i.e., following data collection) research question.

A priori hypotheses:

1) Given the role of parent and friend relationships in psychosocial adjustment, we hypothesized negative associations between parent relationship quality and loneliness as well as friend relationship quality and loneliness at baseline.

2) We hypothesized there would be a difference in the magnitude of the negative association between relationship quality and baseline loneliness for parents compared to friends given their differing influences on young adults. Because prior work has independently linked both parent and friend relationship quality to wellbeing in young adults, this hypothesis was non-directional. 
3) We hypothesized that baseline loneliness would be lowest for individuals with both high parent and high friend relationship quality. In other words, parent and friend relationship quality would interact with each other to predict lower levels of loneliness (McCabe, Kim, \& King, 2018).

4) We hypothesized that high relationship quality with parents and friends at baseline would predict less loneliness one month and two months post-baseline.

Exploratory research question:

1) What are typical trajectories of loneliness across the first year of college? We aimed to characterize loneliness trajectories and contextualize the longitudinal effects of parent and friend relationship quality on loneliness.

\section{Methods}

\section{Participants}

The study sample consisted of $101\left(\mathrm{M}_{\mathrm{age}}=18.36, \mathrm{SD}=0.48\right.$, range $=18-19 ; 80$ female $)$ first-year college students from a large, public university in the Western United States. Participants reported their race as 37\% Asian, 27\% Caucasian, 10\% African American, 2\% Native American Indian or Alaska Native, 12\% multiracial, 8\% other, and 4\% declined to report. Additionally, 24\% of participants self-identified as Hispanic or Latinx.

\section{Procedure}

First-year college students were contacted during their first quarter of college via their university emails with an invitation to participate in the study. Participants were eligible if they were 18-25 years old, were first-year freshman college students, spoke English fluently, and did not have any serious health conditions. Individuals who expressed interest and qualified following a brief screening were scheduled for an in-person lab session during their first or second quarter of college, depending on availability. Upon arriving at the lab session, participants completed informed consent. The lab session consisted of completing various selfreport measures and computerized assessments. All measures that were used for this study are described below; unanalyzed measures collected are disclosed in the Supplement. Similarly, all 
analyses conducted for this study are disclosed here or in the Supplement. Participants were compensated \$20 (USD) for their participation in the baseline session.

Following the laboratory visit, participants completed two online follow-up assessments during the same academic year, consisting of self-reported loneliness (along with other orthogonal measures), one month and two months after baseline. Data collection for this report took place between November 14th, 2019 (approximately five weeks into the fall quarter) and May 20th, 2020 (approximately half-way through the spring quarter). The initial study was slated to end after the third timepoint, but additional waves of data collection occurred beyond the academic year for the purpose of collecting data specifically about the COVID-19 pandemic. These data were not analyzed here due to extending beyond the focus of the current research questions. Attrition over the study was minimal -- 94 participants provided complete data for all three time points, 3 participants provided data for two time points, and only 4 participants provided data for only one time point, totaling 292 available data points for longitudinal analysis. All participants provided data for the first time, rendering 101 data points for baseline analysis. Figure 1 visualizes the timing of data collection for each participant. Participants were compensated \$25 for participating in the longitudinal portion of the study. The local Institutional Review Board approved all procedures and methods. Data, materials, and analysis code for this study are publicly available on the Open Science Framework (https://osf.io/4x6ef/?view_only=0f26f80e454a4c98aa7fe456745c84c1, blinded link).

\section{Measures}

Parent and Friend Relationship Quality. Parent and friend relationship quality were assessed at baseline with the Inventory of Parent and Peer Attachment Mother, Father, and Peer versions (IPPA; Armsden \& Greenberg, 1987). The measure consists of 25 items across three subscales: trust (e.g. "My mother respects my feelings"), communication (e.g. "When we discuss things, my friends care about my point of view"), and alienation (e.g. "I get upset easily around my father”). Participants used a five-point Likert scale to rate the frequency of each item $(1=$ "Almost never or never" to 5 = "Almost always or always"). Negatively worded items were reverse-scored when calculating relationship quality scores. Participants completed the IPPA Mother version to assess their relationship with their mother and responses were averaged into a mean mother relationship quality score (Mother IPPA: $\omega=0.96)$. Likewise, the IPPA Father 
version was completed, if applicable, and responses were averaged into a mean relationship quality score for father (Father IPPA: $\omega=0.96$ ). Mean mother and father relationship quality scores $(r(89)=0.52, \mathrm{p}<0.01)$ were then averaged to yield one parent relationship quality score. Greater scores on the measure indicated stronger parent relationship quality. In the case of participants who only reported relationship quality for one parent $(\mathrm{N}=12)$, responses for the lone parent were used as their final measure of relationship quality. The IPPA Peer version was utilized as a measure of overall, general relationship quality with one's group of friends and responses were averaged to yield one friend relationship quality score (Peer IPPA: $\omega=0.96$ ). Any missing responses to items of the IPPA Mother, Father, or Peer were excluded from the calculation of the mean relationship quality scores.

We also collected a single item measure asking participants to describe the extent to which their interactions with friends were more comprised of those with older (presumably those prior to college), compared to newer (presumably those made at college), friends ("I rely on my old friends more than my new ones"). Participants rated their agreement ("yes") or disagreement ("no") with the item. This item was collected to help unpack any potential effects related to friend relationship quality.

Loneliness. Subjective loneliness was assessed at baseline, one month, and two months later with the UCLA Loneliness Scale (Version 3; Russell, 1996). The UCLA Loneliness Scale consists of 20 items, such as "How often do you feel there is no one you can turn to?" and "How often do you feel left out?”. Participants indicated their responses on a four-point Likert scale (1= "Never" to 4 = "Always"). Positively worded items were reverse-scored and responses were averaged to yield one loneliness score such that higher scores indicated greater levels of loneliness. Any missing responses to items of the loneliness scale were excluded from average loneliness score calculations. Critically, scores from our data evinced good reliability (Time 1: $\omega$ $=0.95$, Time 2: $\omega=0.95$, Time 3: $\omega=0.94)$.

\section{Analysis Plan}

Analyses were completed in two stages: baseline and longitudinal. Baseline analyses allowed us to capture a snapshot of the contemporaneous associations between relationship quality and loneliness at the beginning of the study, whereas longitudinal analyses allowed us to 
track within-person changes in trajectories of loneliness over time. All analyses were conducted using R, the statistical software package (R Core Team, 2020)

\section{Baseline}

We conducted Pearson's correlation analyses using the psych package (Revelle, 2018) to examine the correlation between parent and friend relationship quality and loneliness as well as between parent and friend relationship quality. We then ran two ordinary least squares multiple linear regression analyses using the $\operatorname{lm}$ ( ) function to predict loneliness (dependent variable). First, we assessed independent associations between parent and friend relationship quality (controlling for sex; dummy coded female $=0$, male $=1$ ) and loneliness (hypothesis 1 ). In the second model, we added the interaction term for parent and friend relationship quality (hypothesis 3 ) to the main effects of parent and friend relationship quality, while controlling for sex. Since baseline age was bound between 18 and 19 years, we did not include age as a covariate. We also ran a post-hoc multiple linear regression analysis with an interaction term for friend relationship quality and the single-item question about relying on older or new friends, to test if that moderated the relationship between friend relationship quality and baseline loneliness. Lastly, we computed semi-partial correlations to examine whether there was a difference in the magnitude of the effect of parent and friend relationship quality on loneliness (hypothesis 2). All baseline data were collected prior to the onset of the COVID-19 pandemic.

\section{Longitudinal}

We conducted linear growth curve modeling analyses in a multilevel modeling framework using the nlme package (Pinheiro, Bates, DebRoy, Sarkar, R Development Core Team, 2013) to determine whether parent and friend relationship quality (assessed at baseline) predicted loneliness outcomes longitudinally (hypothesis 4) as well as to characterize normative loneliness trajectories (exploratory research question). Growth curve analyses were chosen as the analysis method given the longitudinal nature of the data and the need to account for timevarying changes in loneliness as well as between-person effects. Our model building and evaluation procedures consisted of a stepwise procedure that involved first specifying the most parsimonious model possible given our hypotheses, and then progressively adding covariates to 
eliminate potential confounds and testing for higher order interaction effects between variables of interest.

Our first modelling step predicted self-reported loneliness as a function of time (coded as days since subject-specific baseline, baseline equaling zero), parent relationship quality, and friend relationship quality while allowing the effect of time and the intercept to vary randomly across participants. The second step included all the aforementioned effects while statistically adjusting for sex (dummy coded female $=0$, male $=1$ ), the academic quarter the participant enrolled in the study (dummy coded fall $=0$, winter $=1$ ), and whether any of a given participant's datapoints were collected during the COVID-19 pandemic (dummy coded all datapoints collected before COVID-19 pandemic $=0$, at least one datapoint collected during COVID-19 pandemic $=1$ ) (all time invariant, between-subject predictors). Given our sample, we defined this variable using the day the university cancelled in-person instruction (March $13^{\text {th }}$, 2020). The third and final step added interaction terms between time and the relationship quality variables (time $\mathrm{X}$ parent relationship quality; time $\mathrm{X}$ friend relationship quality). Parent and friend relationship quality were centered at their respective means before modeling. Additionally, because standard multilevel modeling assumptions of uncorrelated residuals are typically unrealistic in the context of growth curve modeling (Singer \& Willett, 2003), the level 1 error variance/covariance structure was modeled with an imposed first order autoregressive structure $(\mathrm{AR}(1))$. This structure assumes that the covariance in residual within-person errors between two time points with lag $=1$ is greater than a pair of time points with lag $=2$. The multiple equations form of the final model (i.e., that with all predictors included) is notated below and Table 3 contains statistical output for all models.

Within-Person (Level 1):

$$
\text { Loneliness }_{t i}=\pi_{0 i}+\pi_{1 i} \text { Time }_{t i}+e_{t i}
$$

Between-Person (Level 2):

$$
\begin{gathered}
\pi_{0 i}=\gamma_{00}+\gamma_{01} \text { ParentR }_{i}+\gamma_{02} \text { FriendR }_{i}+\gamma_{03} \text { Sex }_{i}+\gamma_{04} \text { Quarter-Start }_{i}+\gamma_{05} \text { Any-COVID } \\
i
\end{gathered}
$$

Loneliness $_{t i}$ refers to the self-reported loneliness scores on the $t$-th day since baseline for the $i$-th individual. The first between-person equation represents the main/simple effects of 
between-person predictors, whereas the second between-person equation summarizes interactions with time (i.e., longitudinal trajectories that change as a function of between-person variables collected at baseline). The fixed-effect intercept $\gamma_{00}$ represents the grand mean loneliness score at baseline for a male participant who began the study in the fall quarter, did not have any follow-up data points collected during the COVID-19 pandemic, and reported average parent and friend relationship quality. The $\gamma_{10}$ coefficient represents the effect of time (in days since baseline) on loneliness, conditional on mean levels of parent and friend relationship quality. The $\gamma_{01}$ and $\gamma_{02}$ coefficients represent the effects of parent relationship quality and friend relationship quality on baseline loneliness (e.g., conditional on time equal to zero); The $\gamma_{03}-\gamma_{05}$ coefficients represent the effects of sex, starting quarter, and the COVID-19 pandemic on loneliness. The $\gamma_{11}$ and $\gamma_{12}$ coefficients respectively represent interactions between time and parent relationship quality, and time and friend relationship quality. In other words, these two coefficients can be interpreted as differences in loneliness trajectories given 1 unit differences in parent and friend relationship quality at baseline. The $u_{0 i}$ term represents the stochastic component of random intercepts, conditional upon parent and friend relationship quality and aforementioned covariates (i.e., a subject-specific deviation from the conditional intercept). The $u_{1 i}$ term represents the stochastic component of random time slopes, conditional upon parent and friend relationship quality (i.e., a subject-specific deviation from a conditional slope of time). Lastly, $e_{t i}$ denotes within-subject error when predicting loneliness from time, between-person predictors, and interaction terms ${ }^{1}$.

We ran additional, supplemental models containing expanded demographic variables that included race, ethnicity, and first-generation status. Because not all participants provided data on race and thus reduced the sample size for these analyses (4 participants, resulting in the loss of 9 longitudinal observations), we only feature models here with variables that had complete data. Notably, the key findings involving time, relationship quality, and their interaction are the same between the models reported here and the supplemental models with additional demographic variables. Findings involving these additional demographics are briefly noted below and reported in greater detail in the Supplement.

\footnotetext{
${ }^{1}$ This model also estimates $\rho$, the first-order autoregressive parameter helps determines covariances between level-1 error at two timepoints pursuant to the form $\sigma^{2}\left(\rho^{\mathrm{h}}\right)$, where $\sigma^{2}$ is the level-1 error variance and $h$ is the lag between timepoints (see Fujikoshi, Kanda, \& Tanimura, 1990).
} 


\section{Results}

\section{Descriptive Statistics}

Means and standard deviations for all study variables are listed in Table 1 and bivariate correlations are presented in Table 2. Loneliness at Time 1, Time 2, and Time 3 were positively correlated with each other. Loneliness was negatively correlated with parent and friend relationship quality at all three time points. Additionally, parent relationship quality was positively correlated with friend relationship quality.

\section{Baseline Analyses}

Multiple linear regression analysis showed negative associations between both parent and friend relationship quality and loneliness at baseline (Parent: $b=-0.28, \mathrm{SE}=0.05, \mathrm{t}(97)=-5.40$, $p<0.001$; Friend: $b=-0.50, \mathrm{SE}=0.06, \mathrm{t}(97)=-8.10, p<0.001)$ (Figures 2 and 3). Post-hoc analyses using the single-item question about relying on older or new friends revealed that relying on friends established prior to college(or, alternately, relying on new friends) did not moderate the effect of friend relationship quality on loneliness $(b=0.07, \mathrm{SE}=0.12, t(95)=0.59$, $p$-value $=0.55)$. Additionally, results showed no significant interaction between parent and friend relationship quality $(b=0.004, \mathrm{SE}=0.087, \mathrm{t}(96)=0.047, p=0.96)$ meaning that the effect of parent relationship quality on loneliness was not dependent on friend relationship quality.

Results from a semi-partial correlation showed that friend relationship quality accounted for more variance in loneliness compared to parent relationship quality: relationship quality with friends uniquely accounted for $29.56 \%$ of the variance in self-reported loneliness after partialling out the effect of parent relationship quality, whereas parent relationship quality uniquely accounted for $13.84 \%$ of the variance in self-reported loneliness.

\section{Growth Curve Modeling}

Results from the modeling procedure are listed in Table 3. After partialling out the effects of between-person covariates (e.g., sex, quarter start, any COVID-19)—none of which were statistically significant - there were significant main effects of parent and friend relationship quality on loneliness as well as a trend towards increased loneliness over time (Figure 4). Step 3 of our modeling procedure showed a significant interaction between friend relationship quality, 
such that the association between friend relationship quality and loneliness was attenuated over time (Figure 5). By contrast, there was no such interaction between parent relationship quality and time, suggesting that association between parent relationship quality and loneliness remained constant over time (Figure 5). These results highlight that trajectories of loneliness during the first year of college are conditional upon levels of relationship quality, and tend to increase overall. Supplementary results showed these interactions were preserved when also controlling for race, ethnicity, and first-generation college student status. These analyses also showed a main effect of race such that non-white participants were lonelier across the study than white participants, but did not exhibit differences in trajectories of loneliness (i.e., there was no interaction between time and race). There were also no interactions between time and firstgeneration student status.

\section{Discussion}

Social relationships can be a powerful source of resilience during times of developmental transition. The transition period from adolescence to adulthood is one of the most critical yet understudied in the lifespan, carrying with it the potential to significantly influence downstream adjustment outcomes. The present study investigated how close relationships affect loneliness during the first year of college, an important 'rite of passage' for many of those transitioning out of adolescence. We found that multiple close relationships can buffer individuals against loneliness during the first year of college, a period characterized by tremendous change. As predicted, there was a negative association between both parent and friend relationship quality and loneliness at baseline. Contrary to our prediction, there was no significant interaction between parent and friend relationship quality, suggesting that the effects of multiple close relationships are additive (i.e., the effect of one variable is constant over all levels of the other). However, these buffering effects observed at baseline had different consequences for trajectories of loneliness. Individuals with high parent relationship quality enjoyed a sustained buffer against loneliness one month and two months after baseline. By contrast, the buffering effect of friend relationship quality on loneliness became attenuated over time. These results contribute to the literature highlighting the importance of close relationships during the transition from adolescence to adulthood, underscore the independent effects of high-quality parent and friend relationships on well-being, and are informative for the development of interventions. 
Independent contributions of parent and friend relationships on loneliness. The present study provides further support for the importance of parents and friends during the first year of college and gives insight into how these relationships contribute to adjustment. Parent and friend relationship quality were negatively associated with loneliness and cumulatively accounted for $43.4 \%$ of the variance in baseline loneliness. Given growing concerns about mental health on college campuses (Pedrelli, Nyer, Yeung, Zulauf, \& Wilens, 2015), this signals close relationships as a contributor to well-being and potential target for interventions. Additionally, the effect of parent relationship quality on loneliness was not dependent on friend relationship quality which is meaningful because it indicates that having both high parent and friend relationship quality does not provide an emergent benefit (i.e., it is not greater than the sum of its part) but also that having low relationship quality with both does not confer additional detriment. Put differently, it means additional improvements in parent (or friend) relationship quality affect individuals the same regardless of whether they are already high or low in friend (or parent) relationship quality. This suggests interventions targeting either parent or friend relationships might be beneficial for improving psychological well-being in college students. In particular, interventions aimed at promoting connectedness and relatedness - either through peer support programs, campus initiatives, or parent involvement - may be particularly valuable. Concretely, such interventions could entail brief, single-session treatments that are logistically favorablesuch as parenting workshops during college move-in on how to stay connected with one's children while supporting their autonomy—or peer counseling programs to help create structured opportunities to establish novel friendships and develop support systems.

These results indirectly suggest that parents and friends play different roles in a young adult's life. Parent-child relationships remain relatively stable throughout college, and having higher parental support during the first year of college is associated with lower loneliness and higher academic persistence (Nicpon, Huser, Blanks, Sollenberger, Befort, \& Kurpius, 2006). Parents are seen as a reliable source of guidance as young adults further individualize (Carlson, 2014; Mattanah, Lopez, \& Govern, 2011). As young adults transition to college, parents are a source of financial support and life advice (Fingerman \& Yahirun, 2016) whereas friends are important for identity formation and fostering autonomy (Barry, Madsen, \& DeGrace, 2016). Interestingly, although young adults rate their parents as the most important people in their lives and refer to their parents for advice on important life decisions, on a day to day basis they seek 
out their friends more to discuss problems and consult their friends on topics such as dating, academic stressors, and college life (Wilks, 1986). When young adults do seek out their parents in making a decision, they seek an additional perspective on the decision rather than a definitive answer of what decision to make (Pizzolato \& Hicklen, 2011).

Friend relationship quality accounted for more variation in baseline loneliness $(29.56 \%)$ compared to parent relationship quality (13.84\%) suggesting that friends may be more adept than parents at fulfilling social needs during the initial transition to college. This is consistent with work by Dennis, Phinney, \& Chuateco (2005), which found that peer support was a stronger predictor of college adjustment than family support. First-year college students exhibit psychological and behavioral phenotypes similar to those of adolescents (Cohen et al., 2016) which together with the social, academic and geographic transitions associated with college might partly explain why they are sensitive to friendship disruptions (Shaver et al., 1985). Relationships with friends in young adulthood are instrumental for identity exploration, meeting social needs and, for new college students, might serve as a marker of integration to college (Barry et al., 2016; Swenson et al., 2008).

Importantly, the present study found that relationship quality with parents and friends not only differentially impacted loneliness at baseline but also longitudinally, reflecting the importance of quality close relationships for overall well-being during young adulthood (Lane \& Fink, 2015). While parent relationship quality continued to predict less loneliness over time, friend relationship quality decreased in predictive power (though it is worth noting the apparent buffer of friend relationship quality on loneliness did not disappear completely). It is possible that over time the contextual factors that influence loneliness during freshman year of college outweigh the benefits of having high friend relationship quality. The diminished relationship between friend relationship quality and loneliness over time might reflect a growing tendency to interact with friends in less satisfying ways (Holtzman, DeClerck, Turcotte, Lisi, \& Woodworth, 2017) - for example, in virtual formats due to increasing academic demands - or changes in friend groups and subsequent fluctuations in social support. In support of this latter possibility, prior research in young adults suggests that network composition turnover can be as high as $40 \%$ in one year (Saramäki, Leicht, López, Roberts, Reed-Tsochas, \& Dunbar, 2014). That parent relationship quality's effects on loneliness did not depend on time suggests that parents may 
serve as pillars of stability in periods of time where individuals experience friendship instability, though more work is needed to directly verify this possibility.

Trajectories of loneliness. We also sought to characterize typical loneliness trajectories in the first year of college. Relative to prior samples of college students, our sample had similar levels of loneliness at baseline (Russell, 1996; Özdemir and Tuncay, 2008; Wei et al., 2005; Kuczynski, Kanter, \& Robinaugh, 2020). Results showed that, after adjusting for covariates, overall loneliness tended to increase over time albeit modestly. It is worth noting that the effect was present across participants regardless of whether they enrolled in the study during the Fall or Winter quarter of their first year of college. It is possible that after the initial novelty and excitement of entering college has subsided, individuals are faced with unmet expectations about college, friendship instability, and the day to day stressors of being a college student (Smith \& Wertlieb, 2005; Shaver et al., 1985; Hurst et al., 2013). Although students often form friendships at the start of college, these relationships are likely not as established as those they had before college, which may leave them without a reliable support network (Shaver et al., 1985). At the same time, relying on high school friends beyond the first few weeks of college can hinder adjustment (Swenson et al., 2008), and relationship satisfaction with close high school friends typically declines across the first year of college (Oswald \& Clark, 2003).

The results of the present study are a departure from prior literature, which has found evidence for decreasing loneliness from the beginning to the end of the first year of college. Cutrona (1982) and Shaver et al (1985) found trends of decreases in loneliness from Fall to Spring of freshman year. Our findings speak to possible changes in the mental health of current cohorts of college students compared to students from forty years ago and even just ten years ago. Emotional well-being of first-year college students has been on a steady decline since 1985, with only $50.4 \%$ of men and $34 \%$ of women reporting above average emotional well-being in 2019 compared to $68.1 \%$ of men and $59.3 \%$ of women in 1985 (Eagan, Stolzenberg, Ramirez, Aragon, Suchard, \& Rios-Aguilar, 2016; Stolzenberg, Aragon, Romo, Couch, McLennan, Eagan, \& Kang, 2020). Additionally, in 2019, 16.6\% of college freshmen reported frequently feeling depressed whereas in 2009 the rate was 6.1\% (Stolzenberg et al., 2020). The present trend in loneliness in college students may also speak to generational differences in loneliness during young adulthood within the context of an ever changing society. A study by Cigna in 2018 found that Generation Z, defined in the study as adults 18-22 (born 1996-2000), is the loneliest 
generation, with $68 \%$ reporting that they feel that no one really knows them well. Given these societal shifts in loneliness trends, it is important to reassess loneliness during young adulthood with each generation and not assume that past trends still apply. Alternately, it is possible that differences between our results and older literature stem from analytic differences given our use of multiple timepoints and growth curve models (Singer \& Willett, 2003; Bollen \& Curran, 2006).

Overall, however, it is necessary to note that trajectories of loneliness were ultimately conditional on levels of friend relationship quality. This reinforces the notion that a 'one-sizefits-all' characterization of the first year of college does not apply to all students-rather, different students go through different experiences that engender different outcomes. This emphasizes a stronger need to perhaps focus on individual differences when studying developmental transitions, especially ones that are structural and social in nature.

Social relationships as a potential intervention target. Loneliness inflicts a toll on wellbeing and has negative downstream consequences, therefore, knowing the effect of parent and friend relationship quality on loneliness can inform interventions. The results of the present study indicate that targeting relationship quality, especially friend relationship quality, could be effective in mitigating loneliness during the first year of college. Interventions for students that are struggling with elevated loneliness could incorporate strategies that improve relationship quality with parents and friends as a means to reduce loneliness. For example, parent relationship quality could be improved by providing more opportunities for freshmen to interact with their parents (e.g., hosting more parent visiting events) and encouraging consistent communication between them. Prior research found that high-quality interactions with parents during freshman year of college predicted greater positive affect and lower negative affect for that particular day (Rogers, Updegraff, Iida, Dishion, Doane, Corbin,Van Lenten, \& Ha, 2018). Meanwhile, friend relationship quality could be targeted through college events that cultivate greater community among first-year students and provide opportunities to meet new people and bond with existing friends. Bohnert, Aikins, \& Edidin (2007) found that participation in community activities fostered greater friend relationship quality in individuals who had poor friend relationships before college. Therefore, encouraging involvement in campus events could be effective in targeting friend relationships. Further, our supplementary findings showing that non-white individuals were more likely to be lonelier than their white counterparts imply further 
intervention specificity. These findings carry importance outside the scope of the first year of college, as they also imply that parent and friend relationship quality can potentially help buttress individuals during other seminal moments early on in adulthood, such as entering the workforce, getting married, or having children. While we have no data to speak directly to this point, it is a noteworthy consideration for future research.

Limitations and Future Directions. The present study has several limitations. Due to the nature of the IPPA Peer survey, we were unable to determine if relationships with new college friends primarily accounted for friend relationship quality scores. This could be addressed in future work by having participants complete the IPPA Peer measure with only their college friends in mind or asking them to specify what friends they were thinking of when completing the questionnaire. Additionally, using the IPPA as our measure of relationship quality provided an overview of parental and friend relationship quality but it does not provide insight into what aspects of the relationship made it high quality ( e.g. responsiveness, level of trust, communication) as well as what feature of high-quality relationships is most influential to loneliness outcomes. Furthermore, the present study assessed trajectories of loneliness during a part of the first year of college, not the entirety of the first year. Future studies would benefit from continuously assessing loneliness over the entire course of the first year of college (i.e., from orientation to the end of freshman year) in order to more comprehensively characterize the trajectory of loneliness across the first year of college.

Future studies might aim to further examine the association between friend relationship quality and loneliness to determine what aspects of friend relationships are particularly helpful in mitigating loneliness. Future work should also assess whether outcomes like depression and anxiety are sensitive to the influence of relationship quality with parents and friends. Given the prevalence of anxiety and depression among college populations (Pedrelli et al., 2015), it would be beneficial to assess whether parent and friend relationship quality could strongly buffer against those psychological outcomes.

A final consideration involves generalizability to other contexts during the transition from adolescence to young adulthood. It may be inappropriate to assume the relationships observed here extrapolate to other contexts (e.g., end of college, individuals attending 2 year programs, trade school, entering the workforce, etc.). While it is a worthwhile point for future research to determine whether the ostensible buffering effects observed here are present in other 
contexts, we remind readers that it may be inappropriate to extrapolate from our current findings without additional work.

Conclusion. The first year of college involves changes that increase the vulnerability to loneliness which is in turn linked to a plethora of negative outcomes. The present study characterized typical trajectories of loneliness and examined whether high-quality relationships with parents and friends could be a potential buffer against loneliness during the first year of college. We found that loneliness increased over time, individuals with high relationship quality with parents and friends had lower loneliness at baseline, and the relationship between parent relationship quality and loneliness stayed constant over time whereas the effect of friend relationship quality was attenuated. Thus, in future work, relationship quality with close others could be targeted to mitigate loneliness which could, in turn, lessen the risk of the negative outcomes associated with loneliness. 
Table 1. Means and Standard Deviations for Study Variables

\begin{tabular}{lcc}
\hline \multicolumn{1}{c}{ Variables } & $\mathrm{N}$ & $\mathrm{M}(\mathrm{SD})$ \\
\hline T1 Loneliness & 101 & $2.18(.57)$ \\
Parent RQ & 101 & $3.53(.77)$ \\
Friend RQ & 101 & $4.12(.63)$ \\
T2 Loneliness & 95 & $2.25(.55)$ \\
T3 Loneliness & 96 & $2.23(.54)$ \\
Sex & & \\
$\quad$ Females & 80 & \\
$\quad$ Males & 21 &
\end{tabular}

Starting Quarter

$\begin{array}{cc}\text { Fall } & 23 \\ \text { Winter } & 78\end{array}$

Any Data During

COVID-19?

Yes $\quad 68$

No $\quad 33$

Note. T1 refers to the first data collection time point, T2 refers to the second data collection time point, and T3 refers to the third data collection time point. T1, T2, and T3 are subject-specific. Starting Quarter refers to the quarter in which participants were enrolled into the study. Any Data During COVID-19 refers to whether participants provided at least one follow-up data point during the COVID-19 pandemic. 
Table 2. Correlation matrix of study variables

\begin{tabular}{|c|c|c|c|c|c|}
\hline Variables & 1. & 2. & 3. & 4. & 5 . \\
\hline 1. T1 Loneliness & 1 & & & & \\
\hline 2. T2 Loneliness & $0.862 * * *$ & 1 & & & \\
\hline 3. T3 Loneliness & $0.812 * * *$ & $0.891 * * *$ & 1 & & \\
\hline 4. Parent RQ & $-0.531 * * *$ & $-0.656 * * *$ & $-0.653 * * *$ & 1 & \\
\hline 5. Friend RQ & $-0.659 * * *$ & $-0.472 * *$ & $-0.487 * *$ & $0.269 * *$ & 1 \\
\hline
\end{tabular}


Table 3. Growth Curve Modelling Results

\begin{tabular}{|c|c|c|c|}
\hline Predictor & Step 1 & Step 2 & Step 3 \\
\hline Intercept & $2.186(0.040)^{* * *}$ & $2.090(0.112)^{* * *}$ & $2.091(0.111)^{* * *}$ \\
\hline Time & $0.001(0.001)$ & $0.001(0.001)$ & $0.001(0.001)^{\prime}$ \\
\hline Parent RQ & $-0.269(0.050)^{* * *}$ & $-0.263(0.051)^{* * *}$ & $-0.277(0.054)^{* * *}$ \\
\hline Friend RQ & $-0.416(0.061)^{* * *}$ & $-0.413(0.064)^{* * *}$ & $-0.486(0.067)^{* * *}$ \\
\hline Sex & - & $0.133(0.093)$ & $0.134(0.093)$ \\
\hline Quarter Start & - & $-0.005(0.146)$ & $-0.005(0.146)$ \\
\hline Any COVID & & $-0.009(0.130)$ & $0.008(0.130)$ \\
\hline $\begin{array}{l}\text { Parent RQ x } \\
\text { Time }\end{array}$ & 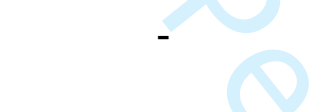 & - & $0.000(0.001)$ \\
\hline $\begin{array}{l}\text { Friend RQ } x \\
\text { Time }\end{array}$ & - & - & $0.003(0.001)^{* *}$ \\
\hline $\operatorname{SD}\left(e_{t i}\right)$ & 0.289 & 0.281 & 0.260 \\
\hline $\operatorname{SD}\left(\pi_{0 i}\right)$ & 0.288 & 0.297 & 0.302 \\
\hline $\operatorname{SD}\left(\pi_{1 i}\right)$ & 0.002 & 0.002 & 0.002 \\
\hline $\operatorname{Cor}\left(\pi_{0 i}, \pi_{1 i}\right)$ & -0.024 & -0.025 & 0.268 \\
\hline AIC & 183.929 & 195.883 & 212.287 \\
\hline $\mathrm{BIC}$ & 216.895 & 239.713 & 263.323 \\
\hline
\end{tabular}

Note: ' $p<.10 * p<.05 * * p<.01 * * * p<.001$; RQ refers to relationship quality obtained via the IPPA self-report instrument, time was coded as days since baseline $($ zero $=$ day of baseline assessment $)$; Sex was dummy coded $(0=$ male, 1 $=$ female); quarter start referred to the academic quarter that a given participant enrolled in (dummy coded $0=$ fall, $1=$ winter); Any COVID referred to whether a participant provided any data during any point during the COVID-19 pandemic (dummy coded $0=$ no data provided during COVID-19 pandemic, $1=$ at least one follow-up data point collected during COVID-19 pandemic). SD refers to standard deviation of conditional random effects; Cor refers to correlations between conditional random effects; AIC/BIC refer to Akaike and Bayesian Information Criterion, respectively. 
Figure 1. Visualization of data collection over time

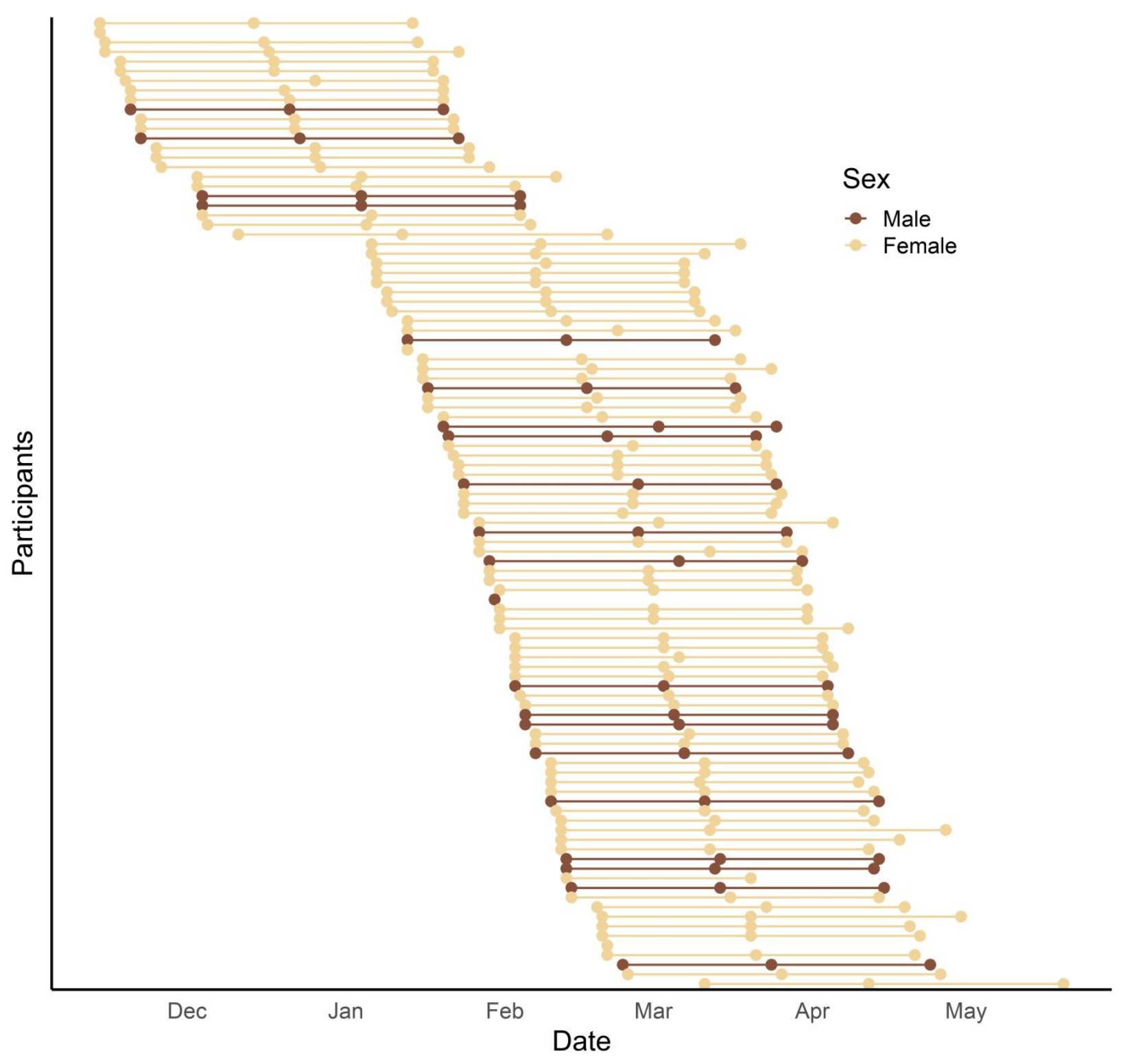


Figure 2. Association Between Parent Relationship Quality and Loneliness at Baseline

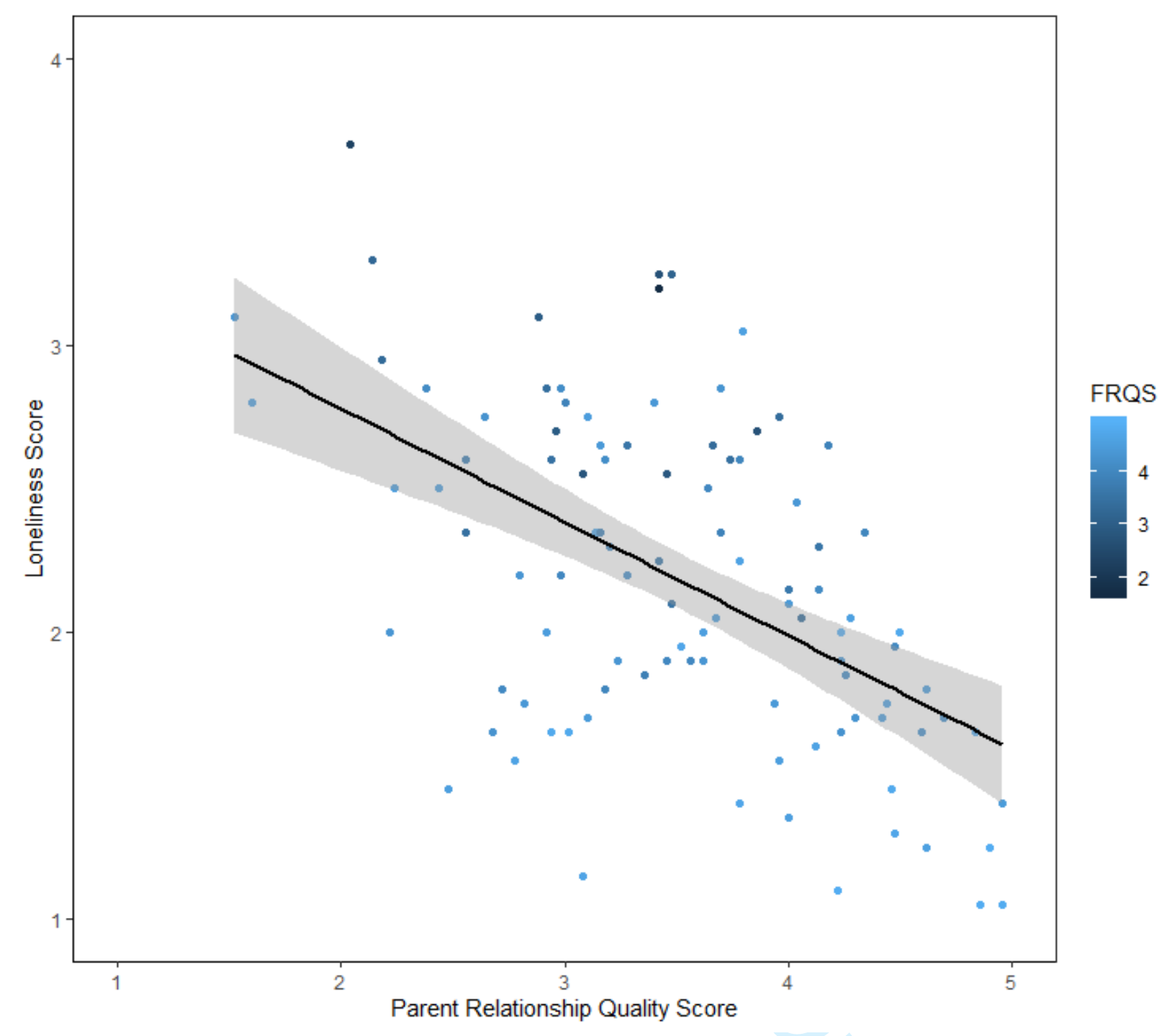

Note. 'FRQS' refers to friend relationship quality score. Parent relationship quality scores could theoretically be equal to one, but we did not observe any such cases in our sample. 
Figure 3. Association Between Friend Relationship Quality and Loneliness at Baseline

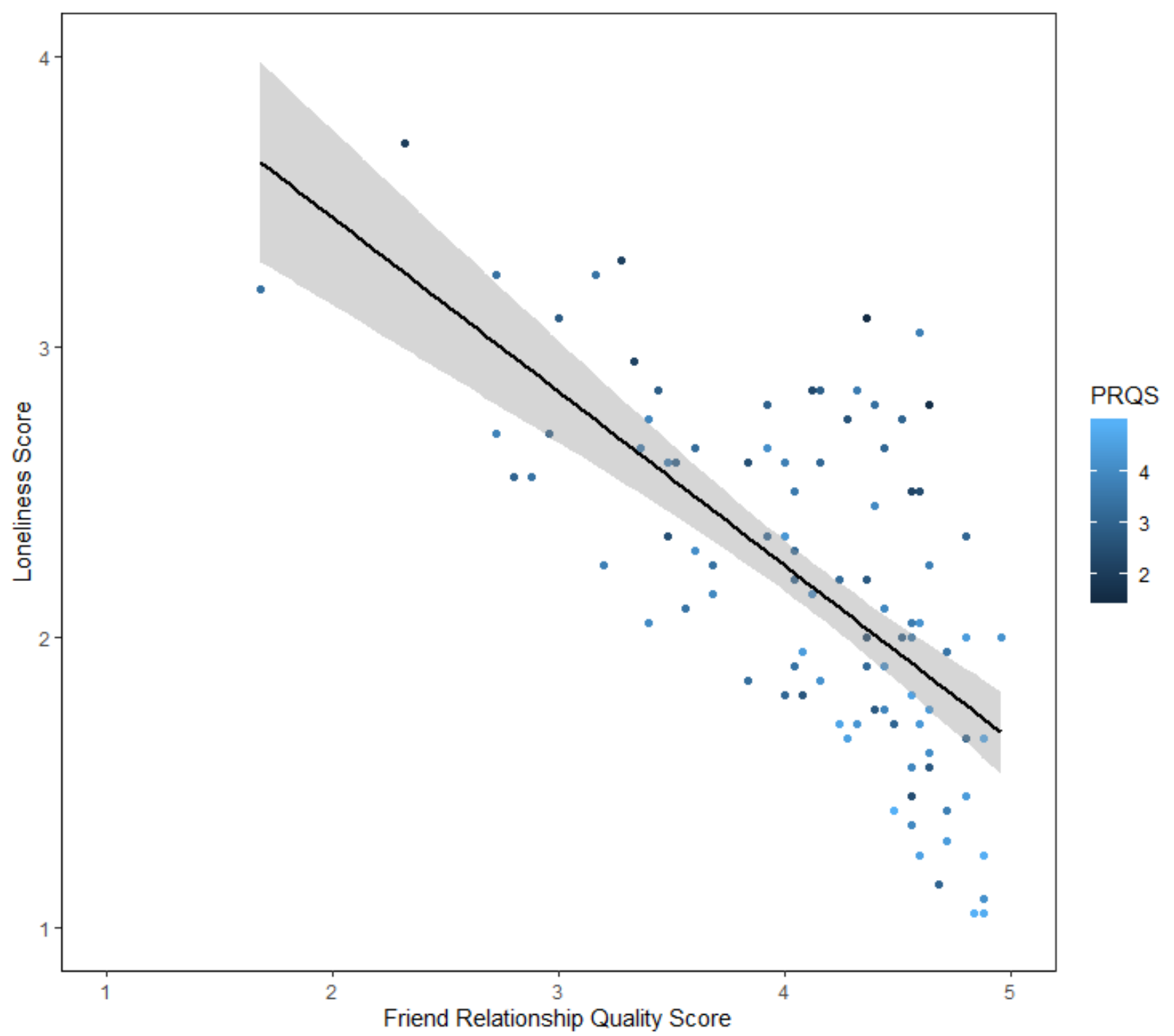

Note. 'PRQS' refers to parent relationship quality score. Friend relationship quality scores could theoretically be equal to one, but we did not observe any such cases in our sample. 
Figure 4. Longitudinal trajectories of loneliness
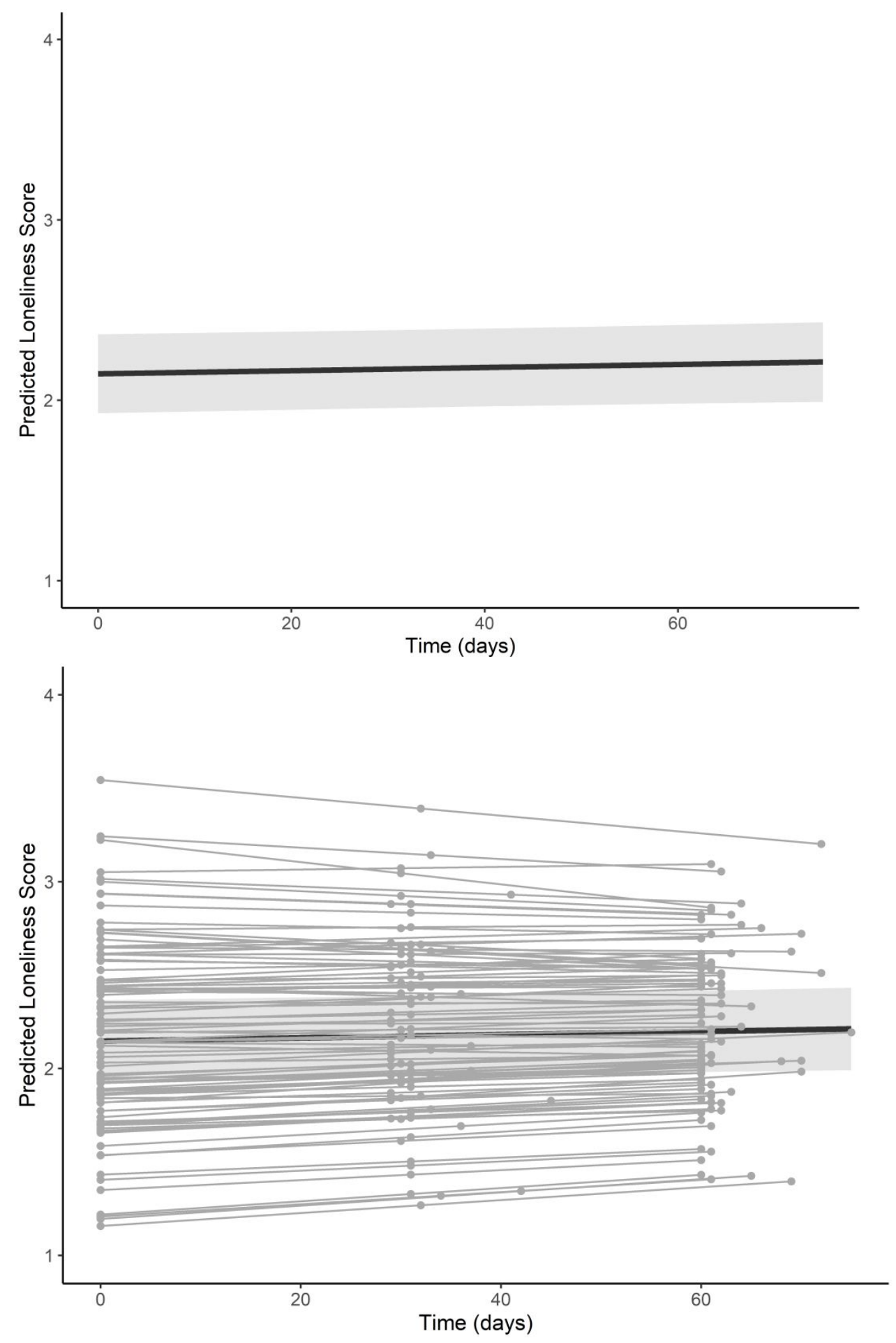

Note. Time is centered on the date of each participant's initial assessment. The top panel shows the fixed effect of the relationship between time and loneliness. The bottom panel superimposes the random effects of each subject on the fixed effect curve. A 95\% confidence interval is depicted. 
Figure 5. Loneliness trajectories as a function of parent and friend relationship quality

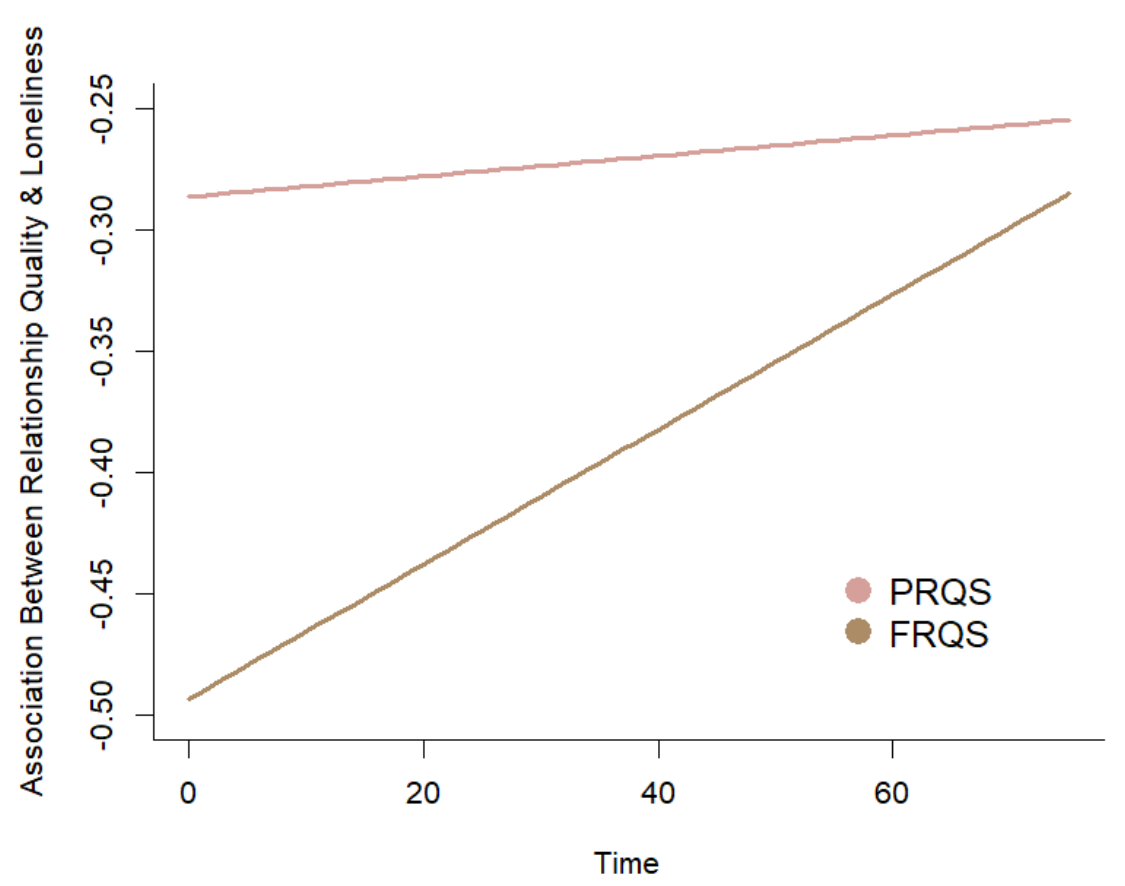

Note. PRQS refers to parent relationship quality score; FRQS refers to friend relationship quality score. Linear Growth Curve refers to the expected trajectory of loneliness over time conditional on a given level of parent or friend relationship quality. Notably, this plot indicates how the association between loneliness and relationship quality changes as a function of baseline, selfreported parent and friend relationship quality. 


\section{References}

Armsden, G. C., \& Greenberg, M. T. (1987). The inventory of parent and peer attachment: Individual differences and their relationship to psychological well-being in adolescence. Journal of Youth and Adolescence, 16(5), 427-454. https://doi.org/10.1007/BF02202939

Arnett, J. J. (2000). Emerging adulthood: A theory of development from the late teens through the twenties. The American Psychologist, 55(5), 469-480. https://doi.org/10.1037/0003066X.55.5.469

Arnett, J. J. (2014). Emerging adulthood: The winding road from the late teens through the twenties. Oxford University Press.

Barry, C. M., Madsen, S. D., \& DeGrace, A. (2016). Growing up with a little help from their friends in emerging adulthood. In The Oxford Handbook of Emerging Adulthood (Vol. 631, pp. 215-229). Oxford University Press, xv.

Bohnert, A. M., Aikins, J. W., \& Edidin, J. (2007). The Role of Organized Activities in Facilitating Social Adaptation Across the Transition to College. Journal of Adolescent Research, 22(2), 189-208. https://doi.org/10.1177/0743558406297940

Bollen, K. A., \& Curran, P. J. (2006). Latent curve models: A structural equation perspective (Vol. 467). John Wiley \& Sons.

Buote, V. M., Pancer, S. M., Pratt, M. W., Adams, G., Birnie-Lefcovitch, S., Polivy, J., \& Winter, M. G. (2007). The Importance of Friends: Friendship and Adjustment Among 1st-Year University Students. Journal of Adolescent Research, 22(6), 665-689. https://doi.org/10.1177/0743558407306344

Cacioppo, J. T., Hawkley, L. C., Crawford, L. E., Ernst, J. M., Burleson, M. H., Kowalewski, R. B., Malarkey, W. B., Van Cauter, E., \& Berntson, G. G. (2002). Loneliness and health: potential mechanisms. Psychosomatic Medicine, 64(3), 407-417. https://doi.org/10.1097/00006842-200205000-00005

Carlson, C. L. (2014). Seeking Self-Sufficiency: Why Emerging Adult College Students Receive and Implement Parental Advice. Emerging Adulthood, 2(4), 257-269. https://doi.org/10.1177/2167696814551785

Caspi, A., Harrington, H., Moffitt, T. E., Milne, B. J., \& Poulton, R. (2006). Socially isolated children 20 years later: risk of cardiovascular disease. Archives of Pediatrics \& Adolescent Medicine, 160(8), 805-811. https://doi.org/10.1001/archpedi.160.8.805 
Center for Collegiate Mental Health. (2019). Center for Collegiate Mental Health: 2018 Annual Report (Publication No. STA 19-180).

Cigna (2018) Cigna US loneliness index. https://www.ipsos.com/sites/default/files/ct/news/ documents/2018-05/us-loneliness-index-report-pr-2018-05-01.pdf. Accessed on 28 Aug 2020

Cohen, A. O., Bonnie, R. J., Taylor-Thompson, K., \& Casey, B. J. (2015). When does a juvenile become an adult: implications for law and policy. Temp. L. Rev., 88, 769.

Cohen, A. O., Breiner, K., Steinberg, L., Bonnie, R. J., Scott, E. S., Taylor-Thompson, K. A., Rudolph, M. D., Chein, J., Richeson, J. A., Heller, A. S., Silverman, M. R., Dellarco, D. V., Fair, D. A., Galván, A., \& Casey, B. J. (2016). When Is an Adolescent an Adult? Assessing Cognitive Control in Emotional and Nonemotional Contexts. Psychological science, 27(4), 549-562. https://doi.org/10.1177/0956797615627625

Conley, C. S., Kirsch, A. C., Dickson, D. A., \& Bryant, F. B. (2014). Negotiating the Transition to College. Emerging Adulthood, 2(3), 195-210. doi:10.1177/2167696814521808

Cutrona, C. E. (1982). Transition to college: Loneliness and the process of social adjustment. Loneliness: A Sourcebook of Current Theory, Research, and Therapy, 36, 291-309.

Cutrona, C. E., Cole, V., Colangelo, N., Assouline, S. G., \& Russell, D. W. (1994). Perceived parental social support and academic achievement: An attachment theory perspective. In Journal of Personality and Social Psychology (Vol. 66, Issue 2, pp. 369-378). https://doi.org/10.1037/0022-3514.66.2.369

Dennis, J. M., Phinney, J. S., \& Chuateco, L. I. (2005). The role of motivation, parental support, and peer support in the academic success of ethnic minority first-generation college students. Journal of College Student Development, 46(3), 223-236. doi:10.1353/csd.2005.0023.

Diehl, K., Jansen, C., Ishchanova, K., \& Hilger-Kolb, J. (2018). Loneliness at Universities: Determinants of Emotional and Social Loneliness among Students. International Journal of Environmental Research and Public Health, 15(9). https://doi.org/10.3390/ijerph15091865

Eagan, M. K., Stolzenberg, E. B., Ramirez, J. J., Aragon, M. C., Suchard, M. R., \& Rios-Aguilar, C. (2016). The American freshman: Fifty-Year trends, 1966-2015. Los Angeles: Higher Education Research Institute, UCLA. 
Fingerman, K. L., \& Yahirun, J. J. (2016). Emerging adulthood in the context of family. In The Oxford Handbook of Emerging Adulthood (pp. 163-176). Oxford University Press New York. https://psycnet.apa.org/fulltext/2015-46837-014.pdf

Gall, T L., Evans, D. R., \& Bellerose, S. (2000). Transition to first-year university: Patterns of change in adjustment across life domains and time. Journal of Social \& Clinical Psychology, 19, 544-567. https://doi.org/10.1521/jscp.2000.19.4.544

Gerdes, H., \& Mallinckrodt, B. (1994). Emotional, Social, and Academic Adjustment of College Students: A Longitudinal Study of Retention. Journal of Counseling \& Development, 72(3), 281-288. doi:10.1002/j.1556-6676.1994.tb00935.x

Gould, R. L. (1972). The phases of adult life: A study in developmental psychology. American Journal of Psychiatry, 129(5), 521-531. https://doi.org/10.1176/ajp.129.5.521

Hawkley, L. C., \& Cacioppo, J. T. (2010). Loneliness Matters: A Theoretical and Empirical Review of Consequences and Mechanisms. Annals of Behavioral Medicine, 40(2), 218227. doi:10.1007/s12160-010-9210-8

Holahan, C. J., Valentiner, D. P., \& Moos, R. H. (1994). Parental support and psychological adjustment during the transition to young adulthood in a college sample. In Journal of Family Psychology (Vol. 8, Issue 2, pp. 215-223). https://doi.org/10.1037/08933200.8.2.215

Holt, L. J., Mattanah, J. F., \& Long, M. W. (2018). Change in parental and peer relationship quality during emerging adulthood: Implications for academic, social, and emotional functioning. Journal of Social and Personal Relationships, 35(5), 743-769. https://doi.org/10.1177/0265407517697856

Holtzman, S., DeClerck, D., Turcotte, K., Lisi, D., \& Woodworth, M. (2017). Emotional support during times of stress: Can text messaging compete with in-person interactions?. Computers in Human Behavior, 71, 130-139. https://doi.org/10.1016/j.chb.2017.01.043

Hurst, C. S., Baranik, L. E., \& Daniel, F. (2013). College student stressors: A review of the qualitative research. Stress and Health, 29(4), 275-285. https://doi.org/10.1002/smi.2465 Inguglia, C., Ingoglia, S., Liga, F., Coco, A. L., \& Cricchio, M. G. L. (2015). Autonomy and relatedness in adolescence and emerging adulthood: Relationships with parental support and psychological distress. Journal of Adult Development, 22(1), 1-13. https://doi.org/10.1007/s10804-014-9196-8 
Kuczynski, A. M., Kanter, J. W., \& Robinaugh, D. J. (2020). Differential associations between interpersonal variables and quality-of-life in a sample of college students. Quality of Life Research, 29(1), 127-139. https://doi.org/10.1007/s11136-019-02298-3

Lane, J. A., \& Fink, R. S. (2015). Attachment, social support satisfaction, and well-being during life transition in emerging adulthood. The Counseling Psychologist, 43(7), 1034-1058. https://doi.org/10.1177/0011000015592184

Lapsley, D. K., \& Hill, P. L. (2010). Subjective invulnerability, optimism bias and adjustment in emerging adulthood. Journal of Youth and Adolescence, 39(8), 847-857. https://doi.org/10.1007/s10964-009-9409-9

Larose, S., \& Boivin, M. (1998). Attachment to Parents, Social Support Expectations, and Socioemotional Adjustment During the High School-College Transition. Journal of Research on Adolescence: The Official Journal of the Society for Research on Adolescence, 8(1), 1-27. https://doi.org/10.1207/s15327795jra0801_1

Larose, S., Guay, F., \& Boivin, M. (2002). Attachment, Social Support, and Loneliness in Young Adulthood: A Test of Two Models. Personality \& Social Psychology Bulletin, 28(5), 684-693. https://doi.org/10.1177/0146167202288012

Lee, C.-Y. S., \& Goldstein, S. E. (2016). Loneliness, Stress, and Social Support in Young Adulthood: Does the Source of Support Matter? Journal of Youth and Adolescence, 45(3), 568-580. https://doi.org/10.1007/s10964-015-0395-9

Levinson, D. J. (1986). A conception of adult development. American psychologist, 41(1), 3.

Lin, S.-H., \& Huang, Y.-C. (2012). Investigating the relationships between loneliness and learning burnout. Active Learning in Higher Education, 13(3), 231-243. https://doi.org/10.1177/1469787412452983

Mattanah, J. F., Lopez, F. G., \& Govern, J. M. (2011). The contributions of parental attachment bonds to college student development and adjustment: A meta-analytic review. Journal of Counseling Psychology, 58(4), 565-596. https://doi.org/10.1037/a0024635

Matthews, T., Danese, A., Gregory, A. M., Caspi, A., Moffitt, T. E., \& Arseneault, L. (2017). Sleeping with one eye open: loneliness and sleep quality in young adults. Psychological Medicine, 47(12), 2177-2186. https://doi.org/10.1017/S0033291717000629

McCabe, C. J., Kim, D. S., \& King, K. M. (2018). Improving Present Practices in the Visual 
Display of Interactions. Advances in Methods and Practices in Psychological Science, 1(2), 147-165. https://doi.org/10.1177/2515245917746792

Merikangas, K. R., He, J. P., Burstein, M., Swanson, S. A., Avenevoli, S., Cui, L., Benjet, C., Georgiades, K., \& Swendsen, J. (2010). Lifetime prevalence of mental disorders in US adolescents: results from the National Comorbidity Survey Replication-Adolescent Supplement (NCS-A). Journal of the American Academy of Child \& Adolescent Psychiatry, 49(10), 980-989. https://doi.org/10.1016/j.jaac.2010.05.017

Merikangas, K. R., He, J. P., Burstein, M., Swendsen, J., Avenevoli, S., Case, B., Georgiades, K., Heaton, L., Swanson, S., \& Olfson, M. (2011). Service utilization for lifetime mental disorders in US adolescents: results of the National Comorbidity Survey-Adolescent Supplement (NCS-A). Journal of the American Academy of Child \& Adolescent Psychiatry, 50(1), 32-45. https://doi.org/10.1016/j.jaac.2010.10.006

Mund, M., Freuding, M. M., Möbius, K., Horn, N., \& Neyer, F. J. (2019). The Stability and Change of Loneliness Across the Life Span: A Meta-Analysis of Longitudinal Studies. Personality and Social Psychology Review, 24(1), 24-52. doi:10.1177/1088868319850738

Nelson, L. J. (2013). Going it alone: Comparing subtypes of withdrawal on indices of adjustment and maladjustment in emerging adulthood. Social Development, 22(3), 522-538.

Nicpon, M. F., Huser, L., Blanks, E. H., Sollenberger, S., Befort, C., \& Kurpius, S. E. R. (2006). The Relationship of Loneliness and Social Support with College Freshmen's Academic Performance and Persistence. Journal of College Student Retention: Research, Theory \& Practice, 8(3), 345-358. https://doi.org/10.2190/A465-356M-7652-783R

Oswald, D. L., \& Clark, E. M. (2003). Best friends forever?: High school best friendships and the transition to college. Personal Relationships, 10(2), 187-196. https://doi.org/10.1111/1475-6811.00045

Özdemir, U., \& Tuncay, T. (2008). Correlates of loneliness among university students. Child and Adolescent Psychiatry and Mental Health, 2(1), 29.https://doi.org/10.1186/1753-2000-229

Pedrelli, P., Nyer, M., Yeung, A., Zulauf, C., \& Wilens, T. (2015). College students: mental health problems and treatment considerations. Academic Psychiatry, 39(5), 503-511. https://doi.org/10.1007/s40596-014-0205-9 
Perlman, D., \& Peplau, L. A. (1998). Loneliness. Encyclopedia of Mental Health, 2, 571-581.

Pinheiro J, Bates D, DebRoy S, Sarkar D, R Development Core Team (2013) Nlme: linear and nonlinear mixed-effects models. R package version 3.1-104.

Pizzolato, J. E., \& Hicklen, S. (2011). Parent involvement: Investigating the parent-child relationship in millennial college students. Journal of College Student Development, 52(6), 671-686. Doi: 10.1353/csd.2011.0081

Ponzetti Jr, J. J. (1990). Loneliness among college students. Family Relations, 336-340. https://www.jstor.org/stable/584881

Pressman, S. D., Cohen, S., Miller, G. E., Barkin, A., Rabin, B. S., \& Treanor, J. J. (2005). Loneliness, social network size, and immune response to influenza vaccination in college freshmen. Health Psychology: Official Journal of the Division of Health Psychology, American Psychological Association, 24(3), 297-306. https://doi.org/10.1037/02786133.24.3.297

Qualter, P., Vanhalst, J., Harris, R., Van Roekel, E., Lodder, G., Bangee, M., Maes, M., \& Verhagen, M. (2015). Loneliness across the life span. Perspectives on Psychological Science: A Journal of the Association for Psychological Science, 10(2), 250-264. https://doi.org/10.1177/1745691615568999

R Core Team (2020). R: A language and environment for statistical computing. R Foundation for Statistical Computing, Vienna, Austria.

Revelle, W. (2018). psych: Procedures for Personality and Psychological Research. Northwestern University, Evanston. R package version 1.8.6

Richardson, T., Elliott, P., \& Roberts, R. (2017). Relationship between loneliness and mental health in students. Journal of Public Mental Health, 16(2), 48-54. https://doi.org/10.1108/JPMH-03-2016-0013

Rogers, A. A., Updegraff, K. A., Iida, M., Dishion, T. J., Doane, L. D., Corbin, W. C., Van Lenten, S. A., \& Ha, T. (2018). Trajectories of positive and negative affect across the transition to college: The role of daily interactions with parents and friends. Developmental Psychology, 54(11), 2181-2192. https://doi.org/10.1037/dev0000598 Rotenberg, K. J., \& Morrison, J. (1993). Loneliness and College Achievement: Do Loneliness Scale Scores Predict College Drop-Out? Psychological Reports, 73(3_suppl), 1283-1288. https://doi.org/10.2466/pr0.1993.73.3f.1283 
Russell, D., Cutrona, C. E., Rose, J., \& Yurko, K. (1984). Social and emotional loneliness: An examination of Weiss's typology of loneliness. Journal of Personality and Social Psychology, 46(6), 1313-1321. https://doi.org/10.1037/0022-3514.46.6.1313

Russell, D. W. (1996). UCLA Loneliness Scale (Version 3): reliability, validity, and factor structure. Journal of Personality Assessment, 66(1), 20-40. https://doi.org/10.1207/s15327752jpa6601_2

Saramäki, J., Leicht, E. A., López, E., Roberts, S. G., Reed-Tsochas, F., \& Dunbar, R. I. (2014). Persistence of social signatures in human communication. Proceedings of the National Academy of Sciences of the United States of America, 111(3), 942-947. https://doi.org/10.1073/pnas.1308540110

Shaver, P., Furman, W., \& Buhrmester, D. (1985). Transition to college: Network changes, social skills, and loneliness. In S. Duck (Ed.), Understanding personal relationships: An interdisciplinary approach , (pp (Vol. 301, pp. 193-219). https://psycnet.apa.org/fulltext/1987-97266-009.pdf

Singer, J. D., Willett, J. B., \& Willett, J. B. (2003). Applied longitudinal data analysis: Modeling change and event occurrence. Oxford university press.

Smith, J. S., \& Wertlieb, E. (2005). Do First-Year College Students' Expectations Align with their First-Year Experiences?, Journal of Student Affairs Research and Practice, 42(2), 299-320. doi: https://doi.org/10.2202/1949-6605.1470

Stolzenberg, E. B., Aragon, M. C., Romo, E., Couch, V., McLennan, D., Eagan, M. K., \& Kang, N. (2020). The American Freshman: National Norms Fall 2019. Los Angeles: Higher Education Research Institute, UCLA.

Swenson, L. M., Nordstrom, A., \& Hiester, M. (2008). The Role of Peer Relationships in Adjustment to College. Journal of College Student Development, 49(6), 551-567. https://doi.org/10.1353/csd.0.0038

Szwedo, D. E., Hessel, E. T., Loeb, E. L., Hafen, C. A., \& Allen, J. P. (2017). Adolescent Support Seeking as a Path to Adult Functional Independence. Developmental Psychology, 53(5), 949-961. https://doi.org/10.1037/dev0000277

Tubman, J. G., \& Lerner, R. M. (1994). Affective experiences of parents and their children from adolescence to young adulthood: stability of affective experiences. Journal of Adolescence, 17(1), 81-98. https://doi.org/10.1006/jado.1994.1008 
Tucker, J. S., Ellickson, P. L., Orlando, M., Martino, S. C., \& Klein, D. J. (2005). Substance use trajectories from early adolescence to emerging adulthood: A comparison of smoking, binge drinking, and marijuana use. Journal of Drug Issues, 35(2), 307-332. https://doi.org/10.1177/002204260503500205

Wei, M., Russell, D. W., \& Zakalik, R. A. (2005). Adult Attachment, Social Self-Efficacy, SelfDisclosure, Loneliness, and Subsequent Depression for Freshman College Students: A Longitudinal Study. Journal of Counseling Psychology, 52(4), 602-614. https://doi.org/10.1037/0022-0167.52.4.602

Wilcox, P., Winn, S., \& Fyvie-Gauld, M. (2005). 'It was nothing to do with the university, it was just the people': the role of social support in the first-year experience of higher education. Studies in Higher Education, 30(6), 707-722. https://doi.org/10.1080/03075070500340036

Wilks, J. (1986). The relative importance of parents and friends in adolescent decision making. Journal of Youth and Adolescence, 15(4), 323-334. https://doi.org/10.1007/BF02145729

Wood, D., Crapnell, T., Lau, L., Bennett, A., Lotstein, D., Ferris, M., \& Kuo, A. (2018). Emerging adulthood as a critical stage in the life course. In Handbook of life course health development (pp. 123-143). Springer, Cham.

Zawadzki, M. J., Graham, J. E., \& Gerin, W. (2013). Rumination and anxiety mediate the effect of loneliness on depressed mood and sleep quality in college students. Health Psychology, 32(2), 212. https://doi.org/10.1037/a0029007 


\section{Supplement}

Parent and Friend Relationship Quality and Trajectories of Loneliness during the First Year of College

\section{Other Measures}

Self-report surveys

*Academic and Non-academic Activities

*Screen for Adult Anxiety Related Disorders Questionnaire (SAARED - AdultVersion)

*Risk Perception Measure (RPM)

*Brief Sensation Seeking Scale (BSSS)

*Center for Epidemiologic Studies Depression Scale (CESD)

*Childhood Trauma Questionnaire -Short Form (CTQ)

*Activities Questionnaire

*Pittsburgh Sleep Quality Index (PSQI)

*Domain-Specific Risk-Taking Adolescent's Scale (DOSPERT-adolescent)

*Expanded Emotion Regulation Questionnaire (E-ERQ)

*Frost Multidimensional Perfectionism Scale (FMPS)

*Implicit Beliefs of Emotion Scale

*Launching Emerging Adults Form (LEAF)

*Patient Health Questionnaire (PHQ-9)

*Rosenberg Self-Esteem Scale

*Social Interaction Anxiety Scale (SIAS)

*Social Networks Questionnaire

*Social Support

*Theories of Intelligence

*Undergraduate Stress Questionnaire

*Ambiguity Tolerance (MSTAT-II)

\section{Computerized tasks}

*Risky Decision-Making Task (Sokol-Hessner et al., 2009; Sokol-Hessner et al., 2015) 
*Vanishing Bandit Task (Navarro et al., 2018)

*Risk Ambiguity Task (Levy et al., 2010; Tymula et al., 2012) 
Supplementary Table 1. Descriptive statistics for additional demographic data

\begin{tabular}{ccc}
\hline Variables & $\mathrm{N}$ & $\mathrm{M}(\mathrm{SD})$ \\
\hline Race & 27 \\
White & 70 \\
Non-White & \\
Ethnicity & 24 \\
Latinx & 77 \\
Not Latinx & \\
First Generation & \\
Yes & 38 \\
No & 63 \\
\hline
\end{tabular}

Note. The 'Race' variable reported here categorized students who indicated Caucasian as their only race as 'White' and those who indicated any other race, or mix of races, as 'Non-White'. We note that this is not an optimal categorization, but note that several races that we assessed had very little participants and it would have been statistically inadvisable to use a set of dummy or effects coded categorical predictors (e.g. grossly imbalance, to few cases to reliably estimate a coefficient for a group, etc.). 'Ethnicity' referred to whether individuals identified as Hispanic/Latinx or not. Notably, these are distinct concepts (one can be racially white and Latinx/Hispanic, or racially Black and Latinx/Hispanic). 'First Generation' refers to whether individuals are the first person in their immediate family to attend college. 
Supplementary Table 2. Growth curve modeling results without imposing AR(1) structure.

\begin{tabular}{|c|c|c|c|}
\hline Predictor & Step 1 & Step 2 & Step 3 \\
\hline Intercept & $2.195(0.039)^{* * *}$ & $2.096(0.113)^{* * *}$ & $2.096(0.113)^{* * *}$ \\
\hline Time & $0.001(0.001)$ & $0.001(0.001)$ & $0.001(0.001)^{\prime}$ \\
\hline Parent RQ & $-0.271(0.051)^{* * *}$ & $-0.264(0.052)^{* * *}$ & $-0.274(0.054)^{* * *}$ \\
\hline Friend RQ & $-0.424(0.062)^{* * *}$ & $-0.419(0.065)^{* * *}$ & $-0.473(0.067)^{* * *}$ \\
\hline Sex & & $0.141(0.094)$ & $0.140(0.094)$ \\
\hline Quarter Start & & $-0.013(0.148)$ & $-0.008(0.148)$ \\
\hline Any COVID & - & $-0.004(0.131)$ & $-0.008(0.131)$ \\
\hline $\begin{array}{l}\text { Parent RQ x } \\
\text { Time }\end{array}$ & - & - & $0.000(0.001)$ \\
\hline $\begin{array}{l}\text { Friend RQ x } \\
\text { Time }\end{array}$ & - & & $0.003(0.001)^{* *}$ \\
\hline $\mathrm{SD}\left(e_{t i}\right)$ & 0.183 & 0.183 & 0.183 \\
\hline $\operatorname{SD}\left(\pi_{0 i}\right)$ & 0.357 & 0.358 & 0.356 \\
\hline $\operatorname{SD}\left(\pi_{1 i}\right)$ & 0.004 & 0.004 & 0.003 \\
\hline $\operatorname{Cor}\left(\pi_{0 i}, \pi_{1 i}\right)$ & -0.077 & -0.075 & -0.030 \\
\hline AIC & 184.339 & 196.027 & 213.550 \\
\hline BIC & 213.643 & 236.205 & 260.941 \\
\hline
\end{tabular}

Note: ' $p<.10 * p<.05 \quad * * p<.01 \quad * * * p<.001$; RQ refers to relationship quality obtained via the IPPA self-report instrument, time was coded as days since baseline (zero $=$ day of baseline assessment); Sex was dummy coded $(0=$ male, 1 $=$ female); quarter start referred to the academic quarter that a given participant enrolled in (dummy coded $0=$ fall, $1=$ winter); Any COVID referred to whether a participant provided any follow-up data during any point during the COVID-19 pandemic (dummy coded $0=$ no data provided during COVID- 19 pandemic, $1=$ at least one data point collected during COVID-19 pandemic). SD refers to standard deviation of conditional random effects; Cor refers to correlations between conditional random effects; AIC/BIC refer to Akaike and Bayesian Information Criterion, respectively. 
Supplementary Table 2. Growth curve modeling results with additional demographic variables

\begin{tabular}{|c|c|c|c|}
\hline Predictor & Step 1 & Step 2 & Step 3 \\
\hline Intercept & $2.178(0.042)^{* * *}$ & $1.898(0.127)^{* * *}$ & $1.923(0.131)^{* * *}$ \\
\hline Time & $0.001(0.001)$ & $0.001(0.001)$ & $0.001(0.001)$ \\
\hline Parent RQ & $-0.277(0.051)^{* * *}$ & $-0.242(0.051)^{* * *}$ & $-0.259(0.056)^{* * *}$ \\
\hline Friend RQ & $-0.415(0.062)^{* * *}$ & $-0.415(0.063)^{* * *}$ & $-0.497(0.069)^{* * *}$ \\
\hline Sex & & $0.165(0.095)$ & $0.166(0.095)$ \\
\hline Quarter Start & & $-0.056(0.149)$ & $-0.051(0.149)$ \\
\hline Any COVID & - & $-0.032(0.134)$ & $-0.036(0.134)$ \\
\hline First Gen & - & $0.084(0.094)$ & $0.082(0.094)$ \\
\hline Ethnicity & - & $0.030(0.110)$ & $0.030(0.111)$ \\
\hline Race & - & $0.244(0.088)^{* *}$ & $0.208(0.096)^{*}$ \\
\hline Race $\mathrm{x}$ Time & - & & $0.001(0.001)$ \\
\hline $\begin{array}{l}\text { Parent RQ x } \\
\text { Time }\end{array}$ & - & & $0.001(0.001)$ \\
\hline $\begin{array}{l}\text { Friend RQ x } \\
\text { Time }\end{array}$ & - & - & $0.003(0.001)^{* *}$ \\
\hline $\operatorname{SD}\left(e_{t i}\right)$ & 0.333 & 0.318 & 0.285 \\
\hline $\operatorname{SD}\left(\pi_{0 i}\right)$ & 0.249 & 0.250 & 0.284 \\
\hline $\operatorname{SD}\left(\pi_{1 i}\right)$ & 0.000 & 0.000 & 0.000 \\
\hline $\operatorname{Cor}\left(\pi_{0 i}, \pi_{1 i}\right)$ & -0.005 & -0.005 & -0.003 \\
\hline AIC & 179.000 & 195.669 & 226.064 \\
\hline BIC & 211.681 & 249.811 & 290.836 \\
\hline
\end{tabular}

Note: ' $p<.10 * p<.05 * * p<.01 \quad * * * p<.001$; RQ refers to relationship quality obtained via the IPPA self-report instrument, time was coded as days since baseline (zero = day of baseline assessment); Sex was dummy coded $(0=$ male, 1 $=$ female); quarter start referred to the academic quarter that a given participant enrolled in (dummy coded $0=$ fall, $1=$ winter); Any COVID referred to whether a participant provided any follow-up data during any point during the COVID-19 pandemic (dummy coded $0=$ no data provided during COVID-19 pandemic, $1=$ 
at least one data point collected during COVID-19 pandemic); First Gen refers to first generation college student status, dummy coded $0=$ no, $1=$ yes; Race was dummy coded $1=$ Non-White, $0=$ White; Ethnicity was dummy coded $1=$ Latinx/Hispanic, $0=$ Not Hispanic/Latinx. $N$ subjects $=97, n$ datapoints $=283$. SD refers to standard deviation of conditional random effects; Cor refers to correlations between conditional random effects; AIC/BIC refer to Akaike and Bayesian Information Criterion, respectively. An AR(1) structure was imposed on the level 1 error covariance matrix for these models. 